\title{
Blind Students' Attitudes towards the Effectiveness of Services of Disability Services Center at Islamic University of Gaza
}

\author{
Ahmed Mohammed Al-Rantisi \\ Assistant Professor \\ Department of Social Work \\ Islamic University of Gaza \\ Gaza, Palestine \\ Email: aalrantisi [AT] iugaza.edu.ps
}

\begin{abstract}
The study aims at determining the effectiveness of the services of the Disability Services Center (DSC) for blind students at the Islamic University in Gaza (IUG). This evaluative study was applied to all blind students enrolled in different IUG faculties. The study applied the comprehensive social survey methodology to 89 students enrolled in the Center during April-May 2018. The study found that the services that achieved a high level of effectiveness from the perspective of blind students are academic services, followed by social, technical and psychological services. Students viewed the Center's small location and shortage of specialists in the disability field among the main barriers to effective provision of services. The study recommends employing specialists in the field of assistive technologies at DSC and to expand the social and psychological services to help integrate blind students in the larger university community.
\end{abstract}

Keywords---- Effectiveness - Services - blind Students

\section{INTRODUCTION}

People with different forms of disability tend to receive local and international attention. Much effort has been exerted to improve the level of social, health, psychological, educational and rehabilitation services offered by staff working in the field of care for the disabled to achieve preventive, curative and developmental goals in this area (United Nations Organization, 2006). In light of the remarkable progress made in the services provided to persons with disabilities in general and persons with visual disabilities in particular, it is necessary to have institutions that are interested in providing the services needed by persons with visual impairment. There must exist quality services to ensure appropriate care for people with visual disabilities. Badawi (1986) defined services as a set of processes and organized efforts of a therapeutic, preventive and developmental nature, that are given to the people and aimed at helping them as individuals or groups to reach a dignified life characterized by good relations and social levels in line with their wishes and potentials and is consistent with their levels and the aspirations of the society in which they live. Barker (1987) defines services as a community-based system that includes programs, services, and privileges designed to help and address the needs of those who suffer socially, economically, educationally or healthily. These services and programs are a necessity for the preservation of society.

Therefore, people with different degrees of visual impairment need to be supported and sponsored through various bodies and institutions to satisfy their basic needs, given that the failure to do so makes the disabled incapable of experiencing social harmony and adjustment and performing their roles successfully (Faraj, 2006). Universities are among the key institutions that provide care services for persons with disabilities, through their various programs, services and activities that help persons with disabilities. Disabled people wishing to enter higher education institutions are faced by various barriers, yet relatively little research has been carried out to find out the level and nature of such obstacles (Baron, Phillips and Stalker, 1996). The close link between the university and society requires the university to always adjust in its structure, functions, programs and research to respond to the evolving changes in the society. This emanates from the premise that universities should be closely connected to people's lives, problems and needs and to the promotion of their psychological, economic, social and cultural levels and welfare (Ahmad, 1996).

Al-Amri (2012) assessed the quality of programs and services offered to students with disabilities at King Abdul Aziz University using a social survey methodology. The study noted that the majority of students with special needs at King Abdul Aziz University believe that the programs offered by the university to students with special needs are effective and efficient. Students also noted that the main obstacles students faced are related to difficulties in their mobility on campus. Abdul-Alim (2014) examined the effectiveness of services and programs for rehabilitation of students with special needs at Fayoum University in Egypt. He found that the percentage of students' benefit from educational services at the Center was medium compared with their benefit from educational and health services. Travis (2014) highlighted the 
strengths of educational services for disabled students in a Hawaiian society such as the dedication of a number of teachers who are doing their best to serve disabled students, yet he pointed out the lack of disabled students to advocate effectively for their needs which leads to the university to pay less attention to attend to their needs more appropriately.

Mohammed's (2016) study emphasized the necessity of continuing evaluation of the professional practices in relation to the services provided for university disability students. In the Zimbabwean context, Mpofu and Shumba (2012) analyzed the responses of a sample of 102 students with visual disabilities in five Open and Distance Learning tertiary institutions. They found that the modes of delivery in these institutions were exclusionary in nature and lacked suitable facilities catering for students with disabilities. Milic Babic and Dowling (2015) investigated how students with disabilities in Croatia perceive support, experience barriers and propose ways for equality of opportunities in the higher education system. Students proposed: investment in adapting buildings, personal assistants, educational grants and transport; coordination within the formal systems from national government to universities and non-governmental organizations.

This study grew out of the researcher's interest in looking into the effectiveness of the services offered by the DSC at IUG given that both are seen as role models for other Gaza-based institutions in this area. Elkin and Molitor (1985) defined effectiveness as the ability and potential of the organization to fulfill its responsibility and objectives and expectations within the internal and external environment surrounding it. Hammam (2011) defined it as the ability to achieve the goals and objectives of the individual or the rate of performance of the organization, or to achieve the goal with as few sources as possible. It is the area through which specific objectives are achieved as a result of professional intervention. The study also aims to assess the degree of attention and care the Center offers to students with visual impairment. This is also related to looking further into ways to improve the provision of services to assist them to continue their academic achievement and achieve their goals. Further, the study aims to identify the barriers that limit the benefit of blind students from these services which may be attributable to the variables (gender, cumulative rate, duration of blindness) in order to improve the quality of services provided to students with disabilities at the (IUG).

The ultimate goal was to develop a proposal to upgrade the services provided by the DSC at IUG in order to improve the level of services and help them to adapt to the university's academic environment in their community. Islamic University of Gaza (IUG) has played a prominent role in this regard, as several centers have been established at the university to serve people with disabilities, the most important of these is the Disability Services Center (DSC), which provides services for the students with visual and motor disabilities.

\section{METHODOLOGY}

This study employed the comprehensive social survey methodology that was applied to a non-probability, purposive sample including all blind students enrolled in all 11 faculties of IUG and are benefiting from the services of the Center for Disability Services (DSC). The number of students who participated in the study was (92) students. Three students were not interviewed as they attended the Center during exams only, and so interviews were conducted with (89) blind students at the center.

The researcher obtained a research ethics statement approving conducting his research and distributing the questionnaire to the participants in the study who consented to take part in the study and were asked to choose their answers accurately and objectively and that they would have pseudonyms. The researcher interviewed all 89 blind students separately during the period from 24/4/2018 to 22/5/2018, and their responses were recorded. The participants were also assured that the research data would be used for academic research purposes and would be kept strictly confidential. Moreover, it was explained to them that their participation in the research was voluntary and the possibility of withdrawal from participation was not ruled out in all stages: before, during and after the actual participation. They were assured that there would be no fi1 nancial cost to be incurred by them. The research aims, methodology, questions and intended benefit were spelled out to the participants, as it represented an opportunity for the participants to share their opinions and attitudes towards improving the level of services provided by the Center for Disability Services for blind students, and that the study recommendations would be shared with the concerned parties both inside and outside the university.

The researcher designed a survey to measure the effectiveness of the services of the (DSC) for the blind students in light of pertinent psychological and social service literature. The survey asked the respondents to report their attitudes towards how effective the (DSC) Services offered to them in five domains. Each domain contained 10 items, with the exception of the domain of psychological services, which contained nine items, thus comprising 49 items in the survey. The survey also contained eight items about respondents' demographic data, thus totaling 57 items in the survey. Demographic data included information about sex, age, level of study, cumulative average, the level of the palm of sight, cause of blindness, duration of blindness, and residence area. 
The effectiveness of each dimension of the scale (weak, medium, high) was measured by subtracting the minimum score from the upper limit of the score $(3-1=2)$ and dividing this range by the number of three response cells $(2$ 33 =0.66). The minimum score is added to determine the effectiveness of the statement, dimension or scale, as follows: arithmetic mean (from 1 to 1.66) weak efficiency, arithmetic mean (from 1.67 to 2.33) medium effectiveness, arithmetic high mean (from 2.34 to 3 ).

Validity of the study instrument was tested by showing it to a number of referees in the field. They all reported that it was valid for administration. The split-half method was used to test reliability of the instrument; it was found that the reliability of the scale was 0.95 . That is, the reliability coefficient was high. Descriptive analysis presents calculations of frequencies, percentages, arithmetic means, standard deviation, total weights, and relative strength of the domain. The researcher then compiled and coded all data which were transferred to SPSS statistical software for analysis.

\section{RESULTS AND DISCUSSION}

\subsection{Demographics}

Data analysis shows that $65.2 \%$ of the respondents were females, while male students were (34.8\%) (see Table 1$)$. $42.7 \%$ of respondents were in the 20-22 year age group, 37.1\% were in the 18-20 year age group, 20.2\% were over than 22 . Further, $34.8 \%$ of respondents were in their first university year, $24.7 \%$ were in their second year, $16.9 \%$ in third year, $20.2 \%$ in their fourth, and $3.4 \%$ in their fifth year of university study. Students' grade point average (GPA) was as follows: very good $(55.1 \%)$, good $(33.7 \%)$ and $11.2 \%$ had excellent grades.

Table 1: Distribution of Respondents according to sex, age, level of study, grade point average, the level of the palm of sight, cause and duration of blindness and residence area

\begin{tabular}{|c|c|c|c|}
\hline Variables & Responses & Frequency & $\%$ \\
\hline \multirow[t]{3}{*}{ sex } & Male & 31 & 34.8 \\
\hline & Female & 58 & 65.2 \\
\hline & Total & 89 & 100 \\
\hline \multirow[t]{4}{*}{ Age(years) } & 18 to $<20$ & 33 & 37.1 \\
\hline & 20 to $<22$ & 38 & 42.7 \\
\hline & $>22$ & 18 & 20.2 \\
\hline & Total & 89 & 100 \\
\hline \multirow[t]{6}{*}{ level of study } & The first & 31 & 34.8 \\
\hline & The second & 22 & 24.7 \\
\hline & The third & 15 & 16.9 \\
\hline & The fourth & 18 & 20.2 \\
\hline & The Fifth & 3 & 3.4 \\
\hline & Total & 89 & 100 \\
\hline \multirow[t]{4}{*}{ grade point average } & Good & 30 & 33.7 \\
\hline & Very good & 49 & 55.1 \\
\hline & Excellent & 10 & 11.2 \\
\hline & Total & 89 & 100 \\
\hline \multirow{3}{*}{ level of the palm of sight } & Total disability & 36 & 40.4 \\
\hline & Partial disability & 53 & 59.6 \\
\hline & Total & 89 & 100 \\
\hline \multirow[t]{3}{*}{ cause of blindness } & Hereditary & 63 & 70.8 \\
\hline & environmental & 26 & 29.2 \\
\hline & Total & 89 & 100 \\
\hline \multirow{4}{*}{ duration of blindness } & $<5$ years & 7 & 7.9 \\
\hline & 6 to $<10$ years & 15 & 16.9 \\
\hline & $>10$ years & 67 & 75.3 \\
\hline & Total & 89 & 100 \\
\hline \multirow[t]{5}{*}{ residence area } & North Gaza Strip & 26 & 29.2 \\
\hline & Gaza & 30 & 33.7 \\
\hline & Central Gaza Strip & 11 & 12.4 \\
\hline & South of the Gaza Strip & 22 & 24.7 \\
\hline & Total & 89 & 100 \\
\hline
\end{tabular}


Respondent's level of the palm of sight was as follows: $59.6 \%$ had partial disability, and $40.4 \%$ suffered total disability. $70.8 \%$ cause of blindness hereditary, while $29.2 \%$ environmental. As for the duration of blindness, $75.3 \%$ of respondents had a duration of blindness over 10 years, $16.9 \%$ were 6-10 years, and 7.9\% were less than five years. Residence areas were as follows: Gaza (33.7\%), while (22.2\%) lived in the north of the Gaza Strip, $(24.7 \%)$ lived in the southern areas of the Gaza Strip, followed by (12.7) who lived in the Central Gaza Strip area.

\subsection{Assessment of the Effectiveness of DSC Services to Blind Students}

The main aim of the study was to assess the students' personal attitudes towards the effectiveness of the DSC services at IUG. Interviews were conducted with all 89 students with visual impairment and the results were shaped by their experience of the various services offered by the center. The results show differences in the students' personal attitudes towards the effectiveness of the services provided by the Center, as shown below and also in Table (2).

\subsubsection{Academic Services}

The educational services provided by the DSC for blind students have a weighted average overall of (2.47), which reflects a high level of efficiency. The researcher explains this result by that fact that the Center gives priority for educational services over the other services provided to students with visual disabilities. These academic services are especially related to facilitating the taking of exams and the provision of especially designed curricula. This is also due to the fact the IUG is an educational institution and therefore it assigns much greater focus to educational services and it instructs the Center to lay out a detailed plan of textbooks, teaching materials, and learning aids such as Braille and magnifying aids and glasses. The university also sets up a special committee to assist students taking their mid and final exams. The university also conducts courses to develop the ways its teaching and administrative staff communicate with blind students and ensure their easy integration with the larger student body.

\subsubsection{Social services}

The social services provided by the DSC for blind students have an overall weighted average of (2.31), which is an average level of efficiency. The researcher relates this result to the fact that DSC organizes summer recreational trips for blind students after the end of the school year. These trips give sufficient opportunity for them to achieve integration into the larger university community and to consolidate social relations and create an atmosphere of respect between the blind students and the Center's administration. The Center also works on getting blind students represented in different social activities and student clubs and the high achievers honored in special events. In addition, the Center works to solve any problems that may arise between students and teachers, especially in relation to regular classroom attendance and submission of home assignments. Special attention is also paid to organizing events on sspecial occasions such as International Day of Persons with Disabilities. These various activities have largely contributed to a medium level of effectiveness of social services.

\subsubsection{Technical services}

The technical services provided by the DSC for blind Students have an overall weighted average of (2.25). It is an average level of efficiency. The researcher relates this result to the Centre's attention to providing the technical tools to the blind students to help them to integrate into the university's academic life. It is considered one of the priorities of the Center's services at the University. Technical services include printing textbooks using Braille and in a magnified form and provision of screen-reader software, audio materials and other braille-related assistive technologies. The Center also conducts workshops for blind or low vision students on how to use such technologies.

This result is consistent with the theoretical framework of the research, which addressed the achievements of the Center for Disability Services, which included the various technical services offered by the Center for blind students. This finding agrees with the result of the Obaid's (2012) study which recommends the use of modern technology with high efficiency to raise the level of effectiveness of mental disability centers in the governmental and private sectors in the capital Amman Governorate.

\subsubsection{Psychological services}

The psychological services provided by the DSC for blind students have an overall weighted average of (2.22), which is an average level of efficiency. This result is related to the psychological services including mentoring, counselling, and guidance that the Center's staff provide despite their lack of specialization in the psychological field. For instance, the Center provides plans and programs to correct certain wrong behaviors among some blind students in addition to cooperating with mental care institutions in the community with regards to some psychological cases among blind students, and the Center holds training courses for blind students for emotional discharge and psychological support. These various activities contributed significantly to the provision of psychological services to an above-average degree of effectiveness.

Therefore, this psychological support reflects positively on their behavior and self-esteem. This finding is consistent with the result of the Zhang's (2016) study, which found that the effectiveness of school mental health services 
for students with disabilities was of high impact suggesting that students with disabilities who received psychosocial interventions had improved.

Table 2. Students' personal attitudes towards the attitudes of the effectiveness of DSC Services

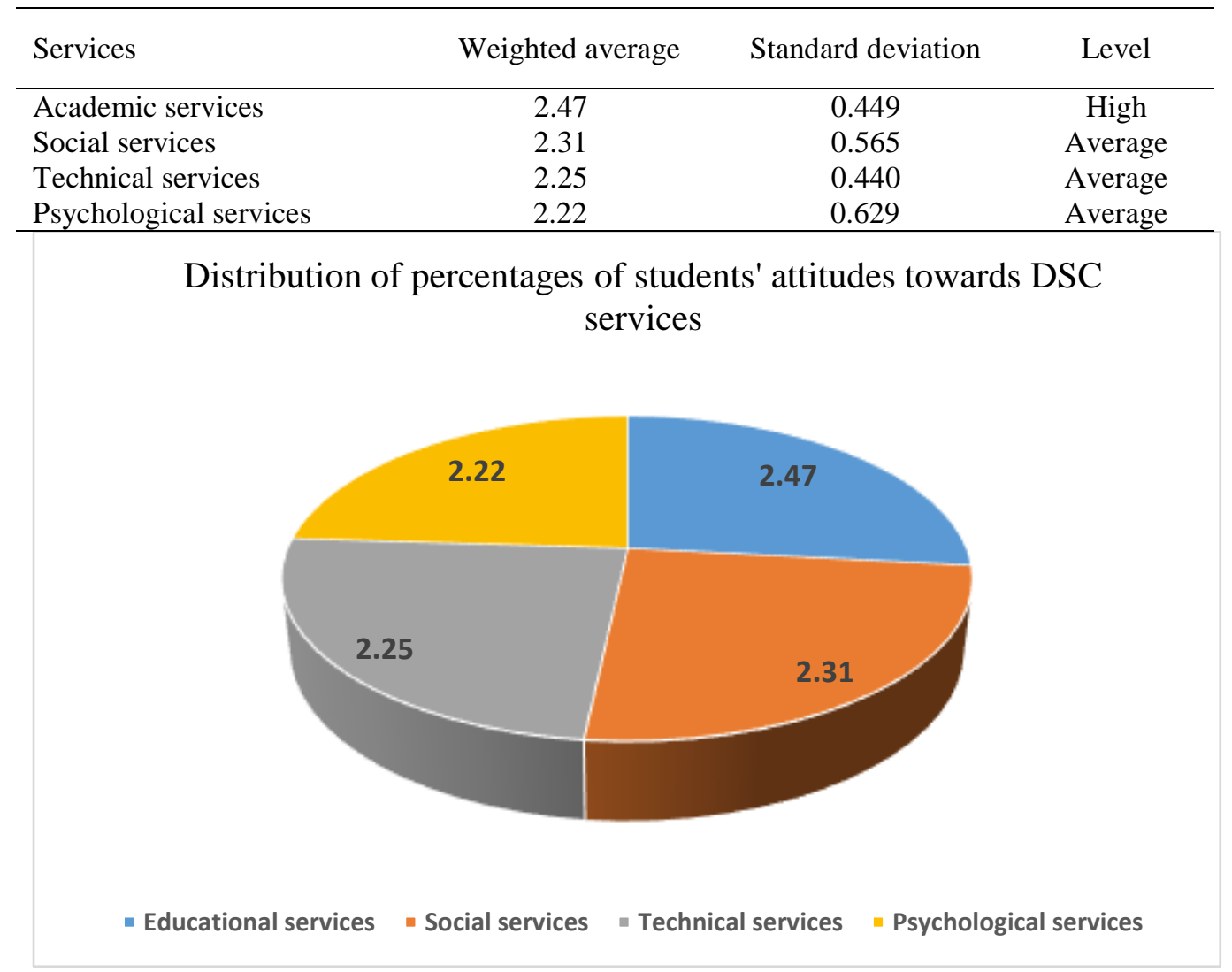

\section{BARRIERS TO THE EFFECTIVENESS OF DSC SERVICES}

The researcher also surveyed the views of the respondents about the obstacles to an effective provision of services by the DSC at IUG. Respondents indicated that the obstacles include inappropriate location and space at the Center, the Center's interest in academic services in the first place, lack of sufficient time for blind students to benefit from the services provided by the Center. The researcher explains this result that the small space in the Center prevents it from the implementation of various social and psychological activities. Since the Center is located in the University's Administration building's basement, this may limit the students' communication with the Center's management and the extent of their benefit from its service, especially psychological and social services.

Students also viewed the absence of specialists and technicians with experience in supervising the services provided by the Center for blind students. This result is also consistent with the result of the Naidoo (2011) study, which showed the lack of effectiveness of services provided by the Disability Unit at the University of KwaZulu-Natal, because of the inefficiency of staff providing services to students with disabilities. It also agrees with the result of Walker (2011) study, which recommends professional development for supervisors of disability-related services in community institutions.

The study also found that there were statistically significant differences at less than 0.05 in the respondents' responses to the obstacles to benefiting from the services provided by the DSC in the male category. The researcher relates this result to the lack of interest among male students in the various services compared to female students, who are keen to benefit from the services of the Center through their commitment to come to the Center regularly.

The results show that no statistically significant differences in barriers to benefiting from DSC services in relation to students' GPA. This is attributed to the situation that all blind students irrespective of their different levels of academic achievement were affected by the obstacles restricting their access to the services provided by the (DSC). 
Table (3) Barriers to achieving effective services

\begin{tabular}{|l|l|c|c|l|}
\hline No. & \multicolumn{1}{|c|}{ Obstacles } & Average & $\begin{array}{c}\text { Standard } \\
\text { Deviation }\end{array}$ & \multicolumn{1}{|c|}{ Level } \\
\hline 1 & Inappropriate location and space at DSC & 2.44 & 0.738 & High \\
\hline 2 & $\begin{array}{l}\text { DSC's interest in academic services first } \\
\text { Lack of time available for blind students to } \\
\text { benefit from the DSC's services }\end{array}$ & 2.30 & 0.775 & Medium \\
\hline 4 & $\begin{array}{l}\text { Shortage of expert professional staff to } \\
\text { supervise DSC's services }\end{array}$ & 2.27 & 0.809 & Medium \\
\hline 5 & $\begin{array}{l}\text { Level of services does not match blind } \\
\text { students' expectations }\end{array}$ & 2.26 & 0.833 & Medium \\
\hline 6 & $\begin{array}{l}\text { Poor equipment and facilities needed by blind } \\
\text { students }\end{array}$ & 2.20 & 0.800 & Medium \\
\hline 7 & $\begin{array}{l}\text { Difficulty of moving around on campus and } \\
\text { to DSC }\end{array}$ & 2.15 & 0.860 & Medium \\
\hline 8 & $\begin{array}{l}\text { Negative view of the university community } \\
\text { to blind students' abilities }\end{array}$ & 2.11 & 0.818 & Medium \\
\hline 9 & $\begin{array}{l}\text { Lack of attention from DSC staff in providing } \\
\text { services }\end{array}$ & 2.07 & 0.780 & Medium \\
\hline 10 & $\begin{array}{l}\text { Lack of coordination in providing services to } \\
\text { blind students }\end{array}$ & 2.02 & 0.879 & Medium \\
\hline & Overall Mean Average & 2.21 & 0.485 & Medium \\
\hline
\end{tabular}

The researcher also found that there are no statistically significant differences in the obstacles of blind students' benefiting from the services provided by the (DSC) according to the variable of the duration of blindness. It becomes clear that obstacles limiting students' access to DSC services affected all students regardless of the duration for blindness.

\section{CONCLUSION}

The study sought to examine the effectiveness of the services provided by DSC at IUG from the perspective of blind students enrolled at the Center. The study found that students' personal attitudes varied with academic services scoring the highest while the other services had a medium level of effectiveness. The study also looked into the range of barriers hindering students' full access to DSC services. Students viewed the small space where the Center is located, its focus on providing academic services and lack of specialist staff at the center all topped the main barriers facing blind students at IUG.

The researcher recommends that a team of specialists in the field of assistive technologies at the Center for Disability Services at the (IUG) be employed and to equip them with the latest assistive technologies in order to enable blind students to deal with these technologies and assist them in their mobility in classes and the campus. This would help them to realize themselves, especially that there is no team specialized in assistive techniques at the Center. Second, social services need to be expanded to assist blind students to nominate amongst themselves who can represent them in student clubs and various social activities at the university, which helps them achieve social integration in the university community, and raise their voice to demand their student rights. Third, psychological services should be expanded through conducting psychological training courses for blind students, especially with regard to emotional discharge and psychological support. The Center needs to network with mental health centers and institutions in the Gaza Strip to provide those courses and to help students understand their psychological characteristics, develop positive attitudes towards themselves and others, and overcome negative feelings because of their disability.

The Center's location in a small area is an obstacle to the implementation of many academic, social and psychological activities within the Center. Thus, the study sees that rehabilitation of the University's DSC in terms of location, capacity, and equipment is necessary in order to cater more appropriately for the needs of students with visual and hearing disabilities.

Finally, the Center should work on supporting outstanding blind students by providing them with scholarships, after communicating with donor institutions especially those that support this important category of students. As the Center 
suffers from a shortage of equipment and assistive devices, grant funding should be allocated to secure grants to help blind students in their academic study and their integration in the community.

\section{FUNDING}

The researcher received no financial support for the research, authorship, and/or publication of this article.

\section{REFERENCES}

- Abdul Alim, F.M. (2014). The Effectiveness of Services and Programs of the Center for Care and Rehabilitation of People with Special Needs in Fayoum University. Journal of Social Work, (52), 57-104. Retrieved from. http://search.mandumah. com/Record/618054.

- Ahmed, Z.N. (1996). The role of Suez Canal University in serving the local community (Unpublished doctoral dissertation). Ain Shams University, Cairo.

- Alsarie, I.G. (2014). Evaluation of programs and services for children with intellectual disabilities and autism disorders in the light of Jordanian quality standards. Al-Manara Journal for Research and Studies, 20 (2), 9-33. Retrieved from https://search.mandumah.com/Record/770634/Details.

- Badawi, A.Z. (1986). Dictionary of Social Sciences. Beirut: Lebanon Library for Publishing and Printing.

- Barker, R. L.(1987). The Social Work Dictionary (e), Sliver Spring Mary Land, N.A.S.W, P. 154.

- Baron, S., Phillips, R., \& Stalker, K. (1996). Barriers to Training for Disabled Social Work Students. Disability \& Society, 11(3), 361-378. doi:10.1080/09687599627660

- $\quad$ Elkin, Robert \& Molitor.(1985). Management Indicators in Nonprofit Organization (N.Y.), U.S.A., P. 3.

- Faraj, S.B. (2006). Towards a proposed conception of a community-based approach to integration between governmental and non-governmental organizations for the care of mentally disabled children and their families. Journal of Studies of Social Work and Human Sciences, 2 (20). Retrieved from https://search.mandumah.com /Record/257416.

- Halwani, A.A. (2010). The effectiveness of programs of NGOs in the provision of integrated care services for the physically disabled. (Unpublished Master Thesis). Helwan University, Cairo.

- Hammam, S.R. (2001, March). The effectiveness of crisis theory in the service of the individual in the development of social responsibility for divorced women, Paper presented at the 14th Academic Conference, Faculty of Social Work, Helwan University, Cairo, Egypt.

- Milic Babic, M., \& Dowling, M. (2015). Social support, the presence of barriers and ideas for the future from students with disabilities in the higher education system in Croatia. Disability \& Society, 30(4), 614-629. doi:10.1080/09687599.2015.1037949

- Mpofu, J., \& Shumba, A. (2012). Perceived Challenges Faced by Visually-impaired Students in Open and Distance Learning Centres in Zimbabwe. Journal of Social Sciences, 31(2), 127-135. doi:10.1080/09718923.2012.11893021

- Mohamed, I.M. (2016). Evaluation of Services for the Care of Disabled Students in Universities (Unpublished Master Thesis). Helwan University, Cairo.

- Mousa, R.J. (2008). Effectiveness of special education centers in the rehabilitation of people with intellectual disabilities from the point of view of their employees in Khartoum. (Unpublished Master Thesis) Sudan University of Science and Technology, Khartoum.

- Naidoo, A. (2010). Students with disabilities' perceptions and experiences of the disability unit at the University of KwaZulu-Natal, Howard College Campus. Available from http://worldcat.org /z-wcorg/ database.

- Obaid, M.S. (2012). Evaluation of the level of effectiveness of governmental and private mental disability centers in Amman Governorate, Journal of the Islamic University for Educational and Psychological Studies, 20 (2), 95-128. Retrieved from http://www.iugaza.edu.ps/ar/periodical/.

- Omri, R.A. (2012). Social Welfare Special Needs in Higher Education Institutions. Journal of Studies of Social Work and Human Sciencesa, 3 (33), 1001-1108. Retrieved from http://search.mandumah.com/Record/471535.

- Travis, S. N. (2014). Serving Learning Disabled Students in HAWAII's Community Colleges - Stakeholders' Perspectives (Doctoral dissertation). Retrieved from http://hdl.handle.net/10125/100359.

- United Nations Organization (2006). Annual report on the rights of the disabled. Retrieved from http://www2.ohchr.org/english/issues/disability/docs/A.HRC.7.61_ar.doc.

- Walker, D. A. (2011). An Exploration of How Disability Support Services are evaluated in Select Community Colleges. Digital Commons@NLU, Chicago, Illinois. Retrieved from http://digitalcommons.nl.edu/diss/43.

- Zhang, Nan (2016). The Status of School-based Mental Health Services for Students with Disabilities (Doctoral dissertation). Texas A \& M University. Available electronically from http: //hdl .handle .net /1969 .1 /158719. 